\title{
Electrocardiographic Alterations in Patients Hospitalized with Leptospirosis in the Brazilian City of Salvador
}

\author{
Edilson Sacramento, Antonio Alberto Lopes, Everaldo Costa, Olaivio Lima Passos, Yara Aragão Costa, \\ Eliana Dias Matos \\ Salvador, BA - Brazil
}

Objective - To report the frequency and types of electrocardiographic alterations in patients with leptospirosis in the first 24 hours of hospitalization.

Methods - We analyzed the electrocardiograms of 157 patients admitted to the Hospital Couto Maia in the city of Salvador, in the State of Bahia, Brazil, from March 1998 to June 1999. The electrocardiograms were performed in the first 24 hours after hospital admission, independent of the clinical manifestations of the patients.

Results - The mean $\pm S D$ for patients' age was $35.5 \pm$ 13.7 (median $=32$ ) years, and jaundice was present in 95.5\% of them. Alterations in the electrocardiogram were detected in $68.2 \%(107 / 157)$ of the patients $(95 \%$ confidence interval $=60.6 \%-75.1 \%)$. Atrial fibrillation was the most frequent arrhythmia, occurring in 10.8\% (17/157) of the patients. Other frequent findings were alterations in ventricular repolarization detected in $38.9 \%(61 / 157)$ of patients and first-degree atrioventricular block in $10.2 \%$ (16/157). The patients with atrial fibrillation were older and had higher levels of creatinine and aminotransferases.

Conclusion - In this sample, approximately 2/3 of the patients had electrocardiographic alterations after hospital admission. Of the major arrhythmias, atrial fibrillation was the most frequent, and the patients with this arrhythmia had evidence of more severe disease. The relation between the presence and type of electrocardiographic alteration and the prognosis of leptospirosis is yet to be assessed.

Key words: electrocardiography, leptospirosis

Hospital Universitário Professor Edgard Santos da Faculdade de Medicina-UFB and Hospital Couto Maia of the State Health Care Authority of Bahia

Mailing address: Edilson Sacramento - Rua Moacir Leão, 360/1503 B - 40080-

160 - Salvador, BA, Brazil - e-mail: edil.son@ssa.terra.com.br

Received for publication on $1 / 2 / 01$

Accepted on 2/7/01

English version by Stela Maris C. e Gandour
Leptospirosis is a zoonosis of universal distribution, even though more frequent in countries with a tropical climate $^{1}$. The disease is endemic in several Brazilian regions, and epidemics occur in the rainy season ${ }^{2,3}$. Experimental studies in animals and autopsies in human beings have shown that cardiac involvement in leptospirosis is frequent, even though it may occur without clinical manifestations ${ }^{4-7}$. Despite this, few studies exist that report electrocardiographic alterations in patients with leptospirosis.

The estimates of the prevalence of electrocardiographic alterations in leptospirosis have been reported to reach $80 \%^{7-10}$. Nevertheless, the influence of bias in these findings is difficult to eliminate due to the preferential selection of patients with clinical manifestations of cardiac disease. Apparently, Escosteguy et al ${ }^{9}$ conducted the unique study properly designed to assess the electrocardiographic alterations occurring with leptospirosis. This study comprised only 56 patients, and the estimate of prevalence $(71.4 \%)$ had little accuracy. Our study was conducted in the city of Salvador, in the Brazilian state of Bahia, where the incidence of leptospirosis is high ${ }^{11}$. The study aimed at reporting the frequency and types of electrocardiographic alterations in patients with leptospirosis right after hospital admission.

\section{Methods}

We assessed the electrocardiograms of 157 patients admitted to the Hospital Couto Maia, which is a referral center for infectious diseases, from March 1998 to July 1999. These patients participated in a randomized clinical trial developed to assess the efficacy of penicillin in the late phase of leptospirosis (ie, symptomatic disease lasting more than 4 days). All participants signed a written informed consent, which had been agreed on by the local committee on ethics. The electrocardiograms were systematically performed, independent of the patients' clinical findings, in the first 24 hours after hospital admission. The electrocardiographic tracings were analyzed by the same cardiologist, who had no previous knowledge of patients' clinical 
findings. A standardized questionnaire was used for reporting the cardiac alterations, including the presence of arrhythmias, hypertrophy of the cardiac chambers, disorders of cardiac conduction, and alterations in ventricular repolarization.

The diagnosis of leptospirosis was established based on clinical and epidemiological data, and on the macroscopic agglutination $(\mathrm{n}=157)$ and microscopic agglutination $(n=19)$ tests for leptospire. The microscopic agglutination tests were performed in the Centro de Pesquisas da Fundação Osvaldo Cruz - FIOCRUZ, and the macroscopic agglutination tests were performed in the Laboratório Central do Estado da Bahia (LACEN). The microscopic agglutination test was considered positive when the titer increased more than 4 times in paired serums or when the titer was greater than 1:800 in a single sample. The macroscopic agglutination test was classified as positive or negative.

The Fisher exact and Kruskal-Wallis tests were used for comparing categorical and quantitative variables, respectively. The accuracy of the prevalence of electrocardiographic alterations was estimated using the $95 \%$ confidence interval (CI), an exact method (mid-p), and the CONFINT module of Computer Programs for Epidemiologists ${ }^{12}$. For the Fisher exact test, the Exact 2xk module of the same software was used. The other analyses were performed with the Statistical Package for Social Science (SPSS) software ${ }^{13}$.

\section{Results}

All patients had positive macroscopic agglutination tests for leptospirosis. The characteristics of the 157 patients in general and stratified into 3 levels according to the type of electrocardiographic findings are shown in table I. The electrocardiogram was initially classified as normal $(\mathrm{n}=50)$, with atrial fibrillation $(\mathrm{n}=17)$, and with other alterations $(\mathrm{n}=90)$. The mean $( \pm \mathrm{SD})$ age in the general group was $35.5 \pm 13.7$ (median $=32$ ) years. Predominance $(89.8 \%$ ) of the male sex was observed; $95.5 \%$ of the patients were icteric. The mean $( \pm \mathrm{SD})$ duration of the symptoms was $6.6 \pm 1.7$ (median $=6$ ) days. The mean $( \pm \mathrm{SD})$ value of serum potassium was $3.27 \pm 0.65 \mathrm{mEq} / \mathrm{L}$ (median $=3.1 \mathrm{mEq} / \mathrm{L}$ ). The mean $( \pm \mathrm{SD})$ levels of urea and creatinine were $193.8 \pm 118.7 \mathrm{mg} / \mathrm{dL}$ (median $=178 \mathrm{mg} / \mathrm{dL}$ ) and $4.43 \pm 2.12 \mathrm{mg} / \mathrm{dL}$ (median $=4.5 \mathrm{mg} /$ dL), respectively. AST, ALT, and total bilirubin had the following means $( \pm \mathrm{SD})$ : $100.2 \pm 68.3 \mathrm{IU} / \mathrm{L}$ (median $=82 \mathrm{IU} / \mathrm{L})$, $69.9 \pm 56.6 \mathrm{IU} / \mathrm{L}$ (median $=52 \mathrm{IU} / \mathrm{L}$ ) , and $21.4 \pm 13 \mathrm{IU} / \mathrm{L}$ (median=20.9 IU/L), respectively. The AST and creatinine levels were significantly higher in the group with atrial fibrillation ( $P=0.006$ and $P=0.017$, respectively).

The prevalence of electrocardiographic alterations in the patients studied was $68.2 \%(107 / 157), 95 \% \mathrm{CI}=60.6 \%$ $75.1 \%$. Table II shows in detail the percentage distribution of the types of electrocardiographic alterations. Of the major arrhythmias, atrial fibrillation was the most frequent, being present in $10.8 \%$ (17/157) of all electrocardiograms.

\begin{tabular}{|c|c|c|c|c|c|}
\hline \multirow[b]{3}{*}{ Characteristics } & \multicolumn{3}{|c|}{ Electrocardiographic findings } & \multirow[b]{3}{*}{$P$ value } & \multirow[b]{2}{*}{ Total } \\
\hline & Normal & $\begin{array}{c}\text { Atrial } \\
\text { fibrillation }\end{array}$ & $\begin{array}{l}\text { Other } \\
\text { alterations }\end{array}$ & & \\
\hline & $\mathrm{N}=50$ & $\mathrm{~N}=17$ & $\mathrm{~N}=90$ & & $N=157$ \\
\hline \multicolumn{6}{|l|}{ Age (years) } \\
\hline Mean \pm SD & $31 \pm 12.9$ & $49 \pm 13.1$ & $35 \pm 12.7$ & $<0.001$ & $35.5 \pm 13.7$ \\
\hline Median & 27 & 50 & 32 & & 32 \\
\hline Age $\% \geq 45(\mathrm{~N})$ & $18.0(9)$ & $64.7(11)$ & $24.4(22)$ & 0.001 & $26.8(42)$ \\
\hline Male sex \% (N) & $92.0(46)$ & $88.2(15)$ & $88.9(80)$ & 0.822 & $89.8(141)$ \\
\hline \multicolumn{6}{|c|}{ Duration of symptoms (days) } \\
\hline Mean \pm SD & $6.3 \pm 1.4$ & $6.9 \pm 2.5$ & $6.7 \pm 1.7$ & 0.413 & $6.6 \pm 1.7$ \\
\hline Median & 6.0 & 7.0 & 6.0 & & 6.0 \\
\hline Jaundice \% (N) & $92.0(46)$ & $100(17)$ & $96.7(87)$ & 0.434 & $95.5(150)$ \\
\hline \multicolumn{6}{|c|}{ Potassium (mEq/L) } \\
\hline Mean \pm SD & $3.2 \pm 0.5$ & $3.4 \pm 0.7$ & $3.3 \pm 0.7$ & 0.427 & $3.3 \pm 0.6$ \\
\hline Median & 3.1 & 3.4 & 3.0 & & 3.1 \\
\hline \multicolumn{6}{|l|}{ Urea (mg/dL) } \\
\hline Mean \pm SD & $180.4 \pm 114.5$ & $245.2 \pm 102.1$ & $191.5 \pm 122.5$ & 0.072 & $193.8 \pm 118.7$ \\
\hline Median & 164.5 & 216.0 & 177.5 & & 178.0 \\
\hline \multicolumn{6}{|c|}{ Creatinine (mg/dL) } \\
\hline Mean \pm SD & $4.1 \pm 1.9$ & $5.8 \pm 1.8$ & $4.3 \pm 2.2$ & 0.017 & $4.4 \pm 2.1$ \\
\hline Median & 3.9 & 5.6 & 4.5 & & 4.5 \\
\hline \multicolumn{6}{|l|}{ AST (IU/L) } \\
\hline Mean \pm SD & $104 \pm 77.6$ & $131.4 \pm 44.0$ & $91.7 \pm 64.9$ & 0.006 & $100.2 \pm 68.3$ \\
\hline Median & 86.0 & 140.0 & 70.0 & & 82.0 \\
\hline \multicolumn{6}{|l|}{ ALT (IU/L) } \\
\hline Mean \pm SD & $70.5 \pm 53.5$ & $91.2 \pm 72.8$ & $65.4 \pm 54.7$ & 0.095 & $69.9 \pm 56.6$ \\
\hline Median & 52.0 & 63.0 & 49.0 & & 52.0 \\
\hline \multicolumn{6}{|l|}{ TB\# (mg/dL) } \\
\hline Mean \pm SD & $19.7 \pm 13.1$ & $25.7 \pm 9.9$ & $21.6 \pm 13.4$ & 0.153 & $21.4 \pm 13.0$ \\
\hline Median & 19.9 & 30.1 & 20.4 & & 20.9 \\
\hline
\end{tabular}


Atrial fibrillation was also associated with low voltage (3 patients), complete right bundle-branch block (2 patients), and alterations in ventricular repolarization (10 patients). Frequencies of supraventricular and ventricular extrasystoles were 3.8\% (6/157) and 1.9\% (3/157), respectively. Alterations in ventricular repolarization were observed in $38.9 \%$ (61/157) of the tracings, being the most frequent finding in the electrocardiograms. First-degree atrioventricular block was the most common disorder of cardiac conduction, accounting for $10.2 \%$ (16/157) of the electrocardiographic tracings. Left anterior hemiblock (12/157) and disorder of conduction of the right bundle-branch (12/157) had the same $7.6 \%$ frequency. Complete right bundlebranch block was reported in $4.5 \%$ (7/157) of the patients. Left ventricular hypertrophy was observed in $1.3 \%(2 / 157)$ of the patients. In $5.1 \%(8 / 157)$ of the patients, the electrocardiogram was compatible with low voltage (tab. II).

\section{Discussion}

According to the results obtained, alterations in the electrocardiographic tracing could be observed in the first 24 hours of hospitalization in approximately $2 / 3$ of the patients with leptospirosis in Salvador. This finding is in accordance with previous studies also carried out in Brazil ${ }^{6-9}$. However, the present study used a sample almost 3 times greater than those used in previous studies, which resulted in a greater accuracy in the estimate of prevalence of electrocardiographic alterations. Of the major arrhythmias, atrial fibrillation was the most frequent $(10.8 \%)$. Alterations in ventricular repolarization (38.9\%) and first-degree atrioventricular block (10.2\%) were other frequent findings.

It is worth noting that more than $70 \%$ of the patients were younger than 45 years, an age bracket in which the elevated frequency of arrhythmias, particularly atrial fibrillation, found in our study is not expected ${ }^{14,15}$. Therefore, most alterations observed should have been caused by leptospirosis. The mechanisms determining the electrocardiographic alterations were not specifically assessed in the present study. We observed, however, that patients with atrial fibrillation had evidence of greater systemic impairment due to the disease. They had higher levels of
Electrocardiographic alterations in patients with leptospirosis

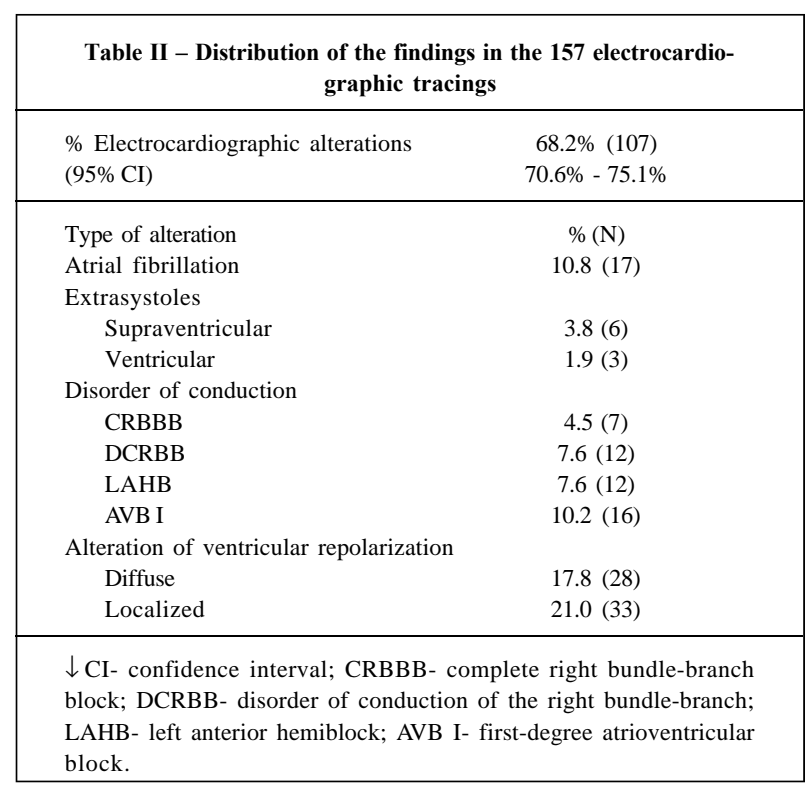

AST and creatinine. It is reasonable to believe that patients with more severe clinical findings have a tendency towards more severe metabolic alterations and greater hemodynamic impairment. It is worth noting that myocarditis is a frequent autopsy finding in patients with leptospirosis, probably constituting an important cause of arrhythmias in these patients. Even though, in the present study the mean level of potassium was similar in patients with and without electrocardiographic alterations, we cannot discount the possibility that hypokalemia and other alterations contribute to arrhythmias in these patients.

According to our results, the prevalence of electrocardiographic alterations in patients with leptospirosis right after hospitalization is high. Of the major arrhythmias, atrial fibrillation was the most frequent, and patients with this arrhythmia had more severe disease. New studies are required for a better understanding of the mechanisms of the electrocardiographic alterations in leptospirosis. The assessment of whether the presence and type of the electrocardiographic alterations are associated with the prognosis of leptospirosis is also important.

\section{References}

1. Farr R. Leptospirosis. Clin Infect Dis 1995; 21: 1-6.

2. Azevedo R, Corrêa M. Considerações em torno da epidemia de leptospirose na cidade de Recife em 1966. Aspectos epidemiológicos, laboratoriais e clínicos. Rev Inst Adolfo Lutz 1968; 28: 85-111.

3. Ko AI, Galvao Reis M, Ribeiro Dourado CM, Johnson WD, Jr., Riley LW. Urban epidemic of severe leptospirosis in Brazil. Salvador Leptospirosis Study Group. Lancet 1999; 354: 820-5.

4. de Brito T, Bohm GM, Yasuda PH. Vascular damage in acute experimental leptospirosis of the guinea-pig. J Pathol 1979; 128: 177-82.

5. de Brito T, Morais CF, Yasuda PH, et al. Cardiovascular involvement in human and experimental leptospirosis: pathologic findings and immunohis- tochemical detection of leptospiral antigen. Ann Trop Med Parasitol 1987; 81: 207-14.

6. Herdy GVH, Assis SM, Marins AB, Silva JJP, Ferrari AH. Miocardite na leptospirose: correlação clínico-patológica de 14 casos. Arq Bras Med 1993; 67: 79-84.

7. Meira DA, Wainman JT, Pileggi F, Salles JC, Meira JA, Decourt LV. Comprometimento miocárdico na leptospirose: estudo eletrocardiográfico e anatomo-patológico. Arq Bras Cardiol 1965; 18: 177-94.

8. Machado R, Pondé A, Viana YC, Oliveira G. Alterações cardíacas na doença de Weil. O Hospital 1966; 4.

9. Escosteguy CC, Mansur EM, Alves MLM, et al. Análise do envolvimento cardíaco na leptospirose. Arq Bras Med 1991; 65: 42-8. 
10. Rajiv C, Manjuran RJ, Sudhayakumar N, Haneef M. Cardiovascular involvement in leptospirosis. Indian Heart J 1996; 48: 691-4.

11. Relatório da Avaliação Epidemiológica da Leptospirose no Estado da Bahia. Salvador (Bahia, Brazil): Departamento de Vigilância da Saúde. Secretaria de Saúde do Estado da Bahia, 1996.

12. Abramson JH, Gahlinger PM. Computer Programs for Epidemiologists. Stone Mountain, GA: PEPI: USD Inc., 1999
13. Norusis MJ. Statistical Package for Social Science (SPSS) for Windows: Base system user's. Chicago, IL: SPSS Inc., 1993.

14. Savioli Neto F, Batlouni M, Guedes MCS, Armaganijan D, Faludi AA. Arritmias cardíacas em idosos saudáveis: detecção através da eletrocardiografia dinâmica. Arq Bras Cardiol 1988; 51: 373-5.

15. Carvalho Filho ET, Miotta ST, Alves ATR, Curati JAE, Alencar YMG. Fibrilação atrial crônica no idoso. Arq Bras Cardiol 1991; 57: 109-14

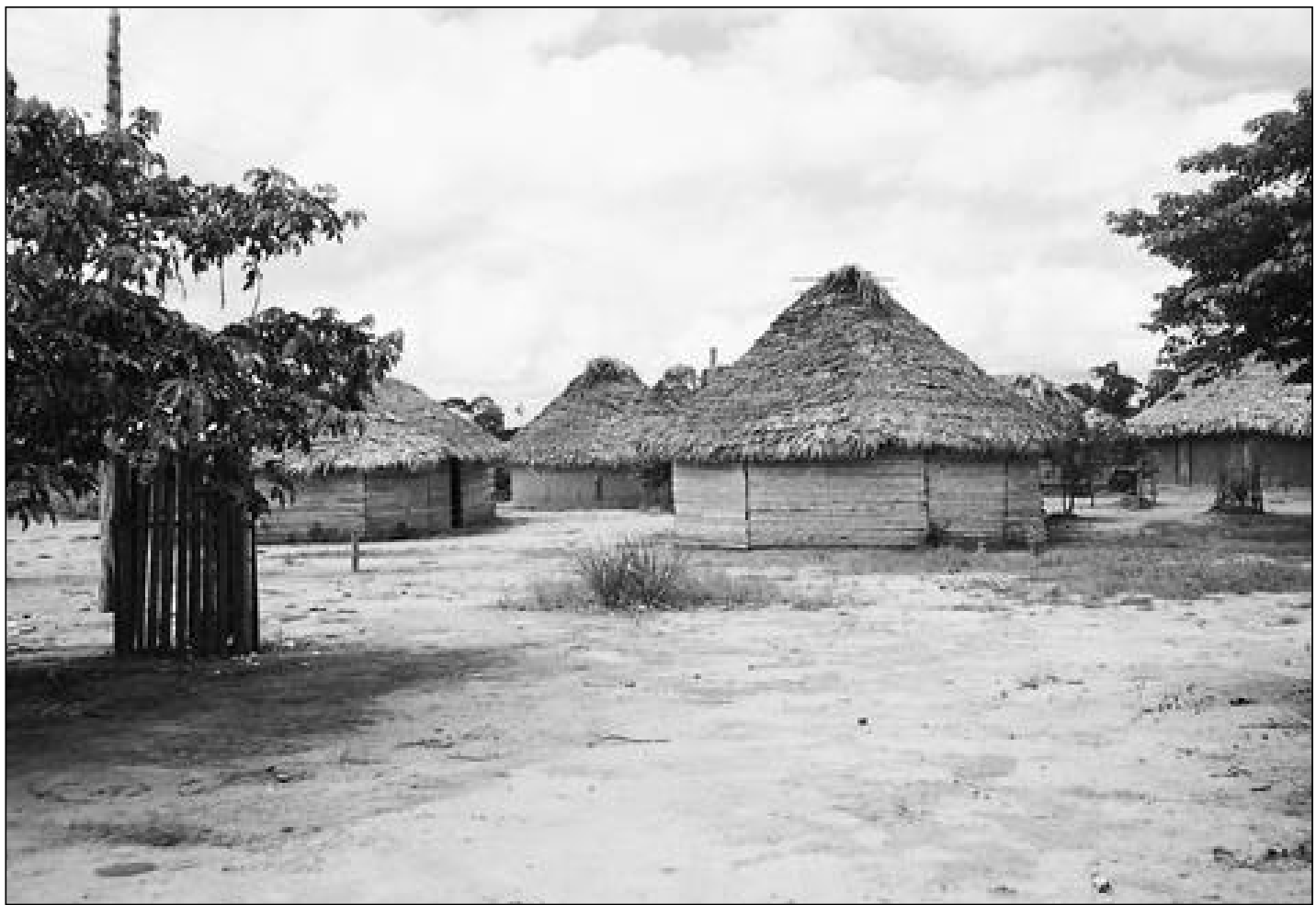

Aldeia dos Índios Waiwai - PA

FernandoKawai-SP

Editor da Seção de Fotografias Artísticas: Cícero Piva de Albuquerque

Correspondência: InCor - Av. Dr. Enéas C. Aguiar, 44 - 05403-000 - São Paulo, SP - E-mail: delcicero@incor. usp.br 